\title{
Acute Illness in the Athlete
}

Carrie A. Jaworski, $\mathrm{MD}^{\mathrm{a}, \mathrm{b}, *}$, Valerie Rygiel, $\mathrm{DO}^{\mathrm{c}}$

\section{KEYWORDS}

- Acute illness • Infectious disease • Pertussis • Influenza • Travelers diarrhea

- Urinary tract infection - Sexually transmitted disease

\section{KEY POINTS}

- Athletes are susceptible to many acute illnesses that can interfere with their ability to train and compete as well as potentially affecting teammates and coaching staff.

- A solid understanding of the preventive measures, diagnosis, and management of such diseases is paramount in the care of an athletic population.

Acute illnesses contracted by athletes typically mirror the type and timing of those seen in the general population; however, in athletes they can present as a significant health burden. When caring for acutely ill athletes, sports medicine providers need to consider how the illness can affect the athlete's training, performance, and competition schedule; the risk of transmission of the illness to other team members; and the necessary precautions and contraindications related to treatment of the athletes and their return to participation. In addition, it is necessary to recognize that athletes training at an elite level, or for more prolonged periods of time, may be more susceptible to illness as a facet of an overtraining syndrome. This article focuses on the impact of acute illness on athletes as well as highlighting special considerations of specific acute illnesses as they relate to athletes.

\section{THE RELATIONSHIP BETWEEN EXERCISE AND IMMUNE FUNCTION}

The proposed effects of exercise on immune function have typically been poorly understood. The literature supports both the positive and negative effects that exercise can have on immune function and risk of illness. ${ }^{1-3}$ The risk of illness has been found to increase in situations of prolonged and/or intense training, especially in athletes who are already immunocompromised, have high levels of intrinsic or extrinsic stressors, or have had a recent infection. ${ }^{4}$ However, most athletes training at a moderate level

a Division of Primary Care Sports Medicine, NorthShore University HealthSystem, Glenview, IL, USA; ${ }^{b}$ Department of Family Medicine, University of Chicago, Pritzker School of Medicine, Chicago, IL, USA; ' Primary Care Sports Medicine Fellowship, University of Chicago/NorthShore University HealthSystem, 2180 Pfingsten Road, Suite 3100, Glenview, IL 60026, USA

* Corresponding author. University of Chicago/NorthShore University HealthSystem Primary Care Sports Medicine Fellowship, 2180 Pfingsten Road, Suite 3100, Glenview, IL 60026.

E-mail address: CJaworski@NorthShore.org 
benefit from improved immune function and lower infection rates compared with people who do not exercise.

Several theories have been proposed in the literature with regard to exercise and immune function, with the 2 most widely accepted being the $\mathrm{J}$-curve model and the open-window theory. The $\mathrm{J}$-curve model is based on evidence that moderate exercise enhances immune function compared with that of sedentary individuals, whereas excessive, intense exercise may paradoxically impair immune function. ${ }^{2}$ This theory is generally accepted as true except in the case of elite, international-level, and medal-winning athletes, in whom high training levels do not impart a negative effect on performance. ${ }^{5-7}$ The reasons for this are unclear, but are thought to be related to self-selection, whereby this group of athletes possess immune systems able to withstand the highest levels of physiologic and psychological stressors, which results in what is referred to as an S-curve phenomenon ${ }^{8}$ (Fig. 1).

The open-window theory proposes that the immune system is temporarily downregulated for a period of time after strenuous exercise, leading to a window in which the risk of infection increases. The depressive effect on immune function can last between 3 and 24 hours after exercise, depending on intensity and duration of the exercise, with greater suppression seen with more intense and prolonged bouts of exercise ${ }^{9}$ (Fig. 2).

Despite these theories, there is limited evidence that showing a direct correlation between exercise-induced impaired immune function and an increased incidence of clinically confirmed infection. ${ }^{1}$

\section{ILLNESS AND PERFORMANCE}

Acute illnesses in athletes stand to affect performance through a variety of mechanisms. Infections occurring during the peak of an athlete's season can impair the athlete's competitive performance because of being limited by symptoms, such as with a persistent cough, as well as via deconditioning from lost training time. In contrast, an infection early in the season is less likely to impart significant consequences because any decline in performance can typically be regained quickly once the illness resolves. Respiratory symptoms such as cough and bronchospasm can directly affect ventilation and aerobic capacity as well as incite anxiety in the athlete because of either a real

\section{The $\mathrm{J}$ and $\mathrm{S}$ Hypothesis}

A Nonelite Athlete

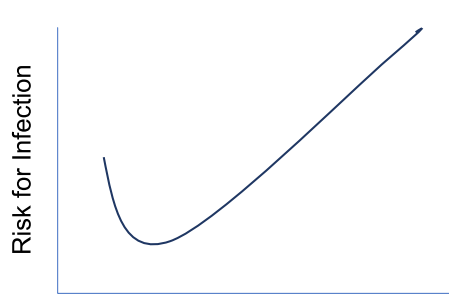

Exercise Intensity
B Elite Athlete



Fig. 1. (A) In nonelite athletes, moderate amounts of exercise decrease the risk for infections, whereas excessive intense exercise increases the risk. (B) Elite athletes are not susceptible to the same negative effect. 


\section{The Open-window Hypothesis}



Time

Fig. 2. The immune system is temporarily downregulated after exercise, leading to a window where in which risk of infection increases.

or perceived inability to oxygenate properly. Fever impairs the ability to regulate body temperature, which increases fluid losses and can affect both stroke volume and cardiac output, affecting maximal oxygen uptake $\left(\mathrm{V}_{2 \mathrm{max}}\right)$. Muscle wasting, impaired coordination, and decreased strength that results from an acute illness can also affect performance as well as increase risk of injury.

Studies have also shown that deconditioning of the cardiorespiratory, musculoskeletal, and metabolic systems can occur in athletes with less than 4 weeks off from training. ${ }^{10}$ The effects are greatest, and occur most quickly, in the most highly trained athletes, sometimes beginning after only 4 to 5 days. ${ }^{11} \mathrm{Vo}_{2 \max }$ can decline between $6 \%$ and $20 \%$ with deconditioning in highly trained athletes, affecting ventilatory efficiency and endurance. ${ }^{12}$ Such decreases in exercise performance can last for 2 to 4 days beyond the complete resolution of an upper respiratory illness in athletes. ${ }^{13}$ Research has shown that maintenance of low-level activity, when appropriate, can be used to fend off some of the physiologic changes associated with complete cessation of activity and should be considered in select cases. ${ }^{12}$

\section{Overtraining and Risk of IIIness}

The concept of overtraining cannot be ignored because it relates to risk of illness in athletes. Training philosophy centers on the idea of functional overreaching, whereby athletes push beyond normal limits in order to adapt to these higher loads and achieve gains in their sports. In order for this overreaching to benefit the athlete, adequate recovery needs to be factored into the equation. In situations in which there is not enough recovery, the athletes fail to improve and may see detrimental effects on their performance either in the form of nonfunctional overreaching or, in more extreme cases, overtraining syndrome. It is here that they are more susceptible to associated rates of increased illness and injury.

Experts have also acknowledged that the congested training and competition schedules of athletes, along with frequent travel, can lend themselves to both psychological and physiologic stress. These stressors can negatively affect health by increasing the risk of both overtraining syndrome as well as of contracting an acute illness. $^{14}$ 
The International Olympic Committee convened an expert consensus group in 2015 that examined these constructs and concluded that the relationship between athletes' health and the loads placed on them should be seen as a well-being continuum along which load and recovery are mutual counteragents. ${ }^{14,15}$ The amount of external and internal loads in the form of both sports-related and non-sports-related stressors places the athletes along a spectrum of health from homeostasis to acute fatigue, overreaching, overtraining syndromes and eventual immune changes, illness, and/or injury. With proper recognition of this disruption of the athlete's homeostasis, usually caused by having to stop for an illness or injury, rest can be initiated, resulting in recovery and return to homeostasis. If symptoms are ignored, this homeostasis remains out of balance and the athlete remains at risk for decreased performance and further illness/injury.

\section{RESPIRATORY INFECTIONS \\ Upper Respiratory Tract Infection}

Upper respiratory tract infections (URTIs) are the most common illnesses to affect both athletic and nonathletic populations alike. It has been reported that a typical adult is afflicted with a URTI 1 to 6 times per year. ${ }^{9}$ Research indicates that more than $50 \%$ of acute illnesses reported during athletic competitions affect the upper respiratory tract. ${ }^{14}$ Most URTIs are self-limited viral illnesses and their evaluation and treatment in athletes are typically the same as those of nonathletes. There are special considerations in athletes with regard to medication choices as well as appropriate timing of return to play.

\section{Cause}

Most URTIs are in the category of the common cold and are caused by rhinoviruses. However, there are several other causative agents to consider because URTIs can also include the following illnesses: bronchitis, pharyngitis, sinusitis, influenza, infectious mononucleosis, and pertussis. Infections tend to occur in early autumn through early spring, with the greatest frequency occurring in the winter months. Athletes may be more at risk if they frequently travel for their sports, compete indoors, or have close contact with teammates and/or opponents. Rates of URTIs in athletes increase in the winter months, most likely because of crowding indoors, seasonal variations in pathogens, and physiologic changes that occur because of the cold. ${ }^{16-18}$ In addition, athletes may be more susceptible to URTIs if they are under increased psychosocial stress, are undergoing a personal crisis, or are experiencing any type of sleep disturbance. ${ }^{19,20}$

\section{Diagnosis and treatment}

URTIs are generally self-limited viral illnesses with the symptoms of rhinorrhea, sore throat, fatigue, nasal congestion, mildly increased temperature, and cough resolving within 7 to 10 days. The diagnosis is typically a clinical one that does not require testing, unless symptoms are prolonged or worsening and other pathogens are being considered.

Treatments often include over-the-counter medications, such as analgesics, antipyretics, and decongestants to aid in relief of symptoms, but these should be used judiciously (Table 1). Expectorants are generally considered safe and can help to thin mucus production. Antipyretics are also appropriate but should not be used solely to control a fever in order to allow participation. Caution should be used with firstgeneration antihistamines because they exert an anticholinergic effect that can result in fatigue, dehydration, and/or heat issues. Care should also be taken when using oral 


\begin{tabular}{|c|c|}
\hline Medication & Potential Concerns in Athletes \\
\hline Antibiotics: overall & $\begin{array}{l}\text { Antibiotic-associated diarrhea } \\
\text { Theoretic risk of fatigue causing increased risk of injury }\end{array}$ \\
\hline Fluoroquinolones & $\begin{array}{l}\text { Tendinopathy } \\
\text { Tendon rupture } \\
\text { QTc prolongation } \\
\text { Photosensitivity } \\
\end{array}$ \\
\hline Macrolides & QTc prolongation \\
\hline Tetracyclines/sulfonamides & Photosensitivity \\
\hline $\begin{array}{l}\text { Antihistamines: } \\
\text { first generation }\end{array}$ & $\begin{array}{l}\text { Anticholinergic effects }=\text { increased risk of dehydration and } \\
\text { heat illness } \\
\text { Sedation }=\text { increased risk of injury }\end{array}$ \\
\hline Antitussives & Fatigue $=$ increased risk of injury \\
\hline Antipyretics & Masks a fever \\
\hline Beta-agonists & $\begin{array}{l}\text { Tachycardia } \\
\text { May be banned in some sports }\end{array}$ \\
\hline Oral decongestants & $\begin{array}{l}\text { Increased risk of heat illness } \\
\text { May be banned in some sports }\end{array}$ \\
\hline
\end{tabular}

decongestants in athletes because of risk of dehydration and hyperthermia, as well as restrictions on their use by certain sport governing bodies. Bronchodilators may be used short term to help with URTI-associated bronchospasm but are prohibited for use in some sports. Practitioners should always refer to the World Anti-Doping Agency (WADA) Web site for the most up-to-date list of prohibited substances if they are treating an Olympic sport athlete. ${ }^{21}$

\section{Prophylaxis}

There is little in terms of preventive treatments against a URTI other than educating the athlete on maintenance of healthy lifestyle habits, such as consuming a nutritious diet, getting adequate sleep, not sharing water bottles, avoiding contact with infected individuals, and the practice of consistent hand washing and good coughing etiquette. Research is ongoing in terms of methods to monitor athletes for subclinical warning signs related to impending illness. At present, coaches and sports medicine staff should ensure adequate recovery is built into training programs, monitor for early signs of overload/overtraining such as fatigue and decreased performance, educate athletes on and encourage healthy habits/hygiene, and provide adequate time for administration of influenza vaccines and other needed immunizations related to travel (Fig. 3).

\section{Acute bronchitis}

Acute bronchitis refers to a cough of infectious origin that lasts for more than 10 days but less than 3 weeks. A persistent cough can wreak havoc on an athlete's performance and training so there is often pressure on the medical team to find a solution.

\section{Cause}

Viruses are the causative agent in acute bronchitis $90 \%$ of the time, $, 9,22$ and include influenza A and B viruses, parainfluenza virus, respiratory syncytial virus, coronavirus, adenovirus, rhinovirus, and metapneumovirus. Bacterial causes include Bordetella pertussis, Chlamydophila pneumoniae, and Mycoplasma pneumoniae. 

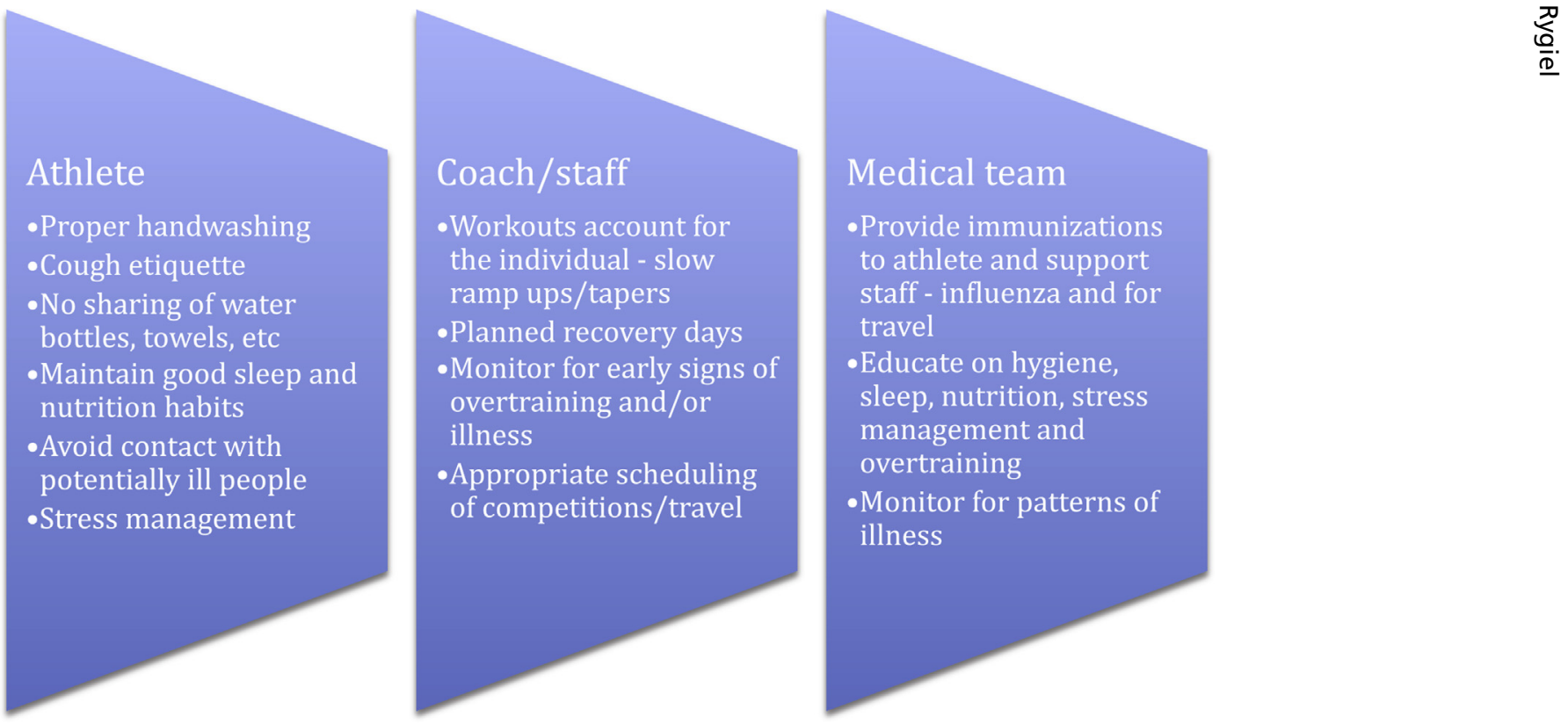

Fig. 3. Approach to prevention of acute illness in athletes.

\section{Medical team}

-Provide immunizations to athlete and support staff - influenza and for travel

-Educate on hygiene, sleep, nutrition, stress management and overtraining

-Monitor for patterns of illness
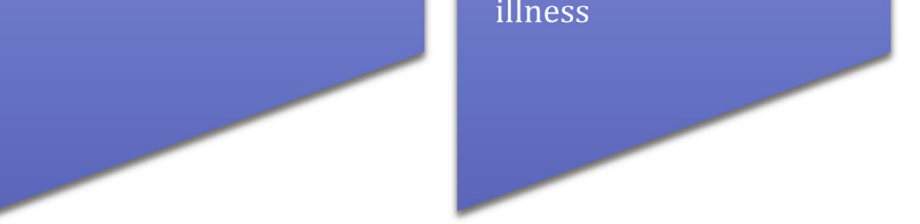


\section{Diagnosis}

Testing seldom needs to be performed to confirm the diagnosis because the diagnosis is made clinically from cough. Fever is unusual in most cases, but can be seen with influenza and pneumonia. Coughs of greater than 3 weeks should prompt investigation for pertussis, keeping in mind that a persistent cough can also be caused by asthma, gastroesophageal reflux, and postnasal drip. ${ }^{23}$

\section{Treatment}

Treatment of acute bronchitis is directed at symptom relief in most cases. Evidence does not support the routine use of antibiotics. ${ }^{23}$ Many athletes, and their coaches, expect antibiotics and it is important to educate them on the rationale for not doing so, which includes the avoidance of both antibiotic-associated diarrhea and antibiotic resistance. ${ }^{23}$

\section{Prophylaxis}

As with most URTIs, there are no known preventive measures other than maintaining a healthy immune system and reducing the spread of infection, as described in Fig. 3.

\section{Pertussis}

As previously mentioned, athletes with a cough lasting greater than 3 weeks warrant further evaluation. Although there are many potential causes of chronic cough, one highly infectious source that needs to be considered is pertussis.

\section{Cause}

Pertussis is an infection caused by the bacterium $B$ pertussis. It is typically spread person to person through aerosolized respiratory droplets. Infections in adults are usually mild and self-limited; nonetheless, a persistent cough can have a significant impact on an athlete's performance in most sports.

\section{Diagnosis}

It can be difficult for clinicians to distinguish pertussis from other causes of chronic cough. Classic pertussis infection is described as having 3 phases of illness: catarrhal, paroxysmal, and convalescent. The catarrhal phase lasts 1 to 2 weeks and is characterized by a mild, intermittent cough, low-grade fevers, and coryza. In the paroxysmal phase, infected individuals experience a spasmodic cough, posttussive emesis, and an inspiratory whoop. This phase can range from 1 to 6 weeks in duration. The convalescent phase is when the symptoms begin to subside, typically over 7 to 10 days, but they can last for months. ${ }^{24}$ The classic symptoms of posttussive emesis and whoop are rarely seen in clinical practice and, although their presence increases the specificity of pertussis, it is not enough to definitively diagnose pertussis. ${ }^{25}$ Confirmatory testing for pertussis is via a nasopharyngeal swab, which can be sent for either culture or polymerase chain reaction (PCR). Results from culture have poor sensitivity and specificity and can take several days to obtain. PCR is costlier, but much quicker, with results available in 1 to 2 days. Because of such limitations, most suspected cases are treated based on patient presentation and ideally include known recent exposure to a confirmed index case. ${ }^{25,26}$

\section{Treatment}

The earlier treatment of pertussis is started, the better. If the patient is able to start treatment in the first 1 to 2 weeks, before the onset of the coughing paroxysms, symptoms may be lessened. For this reason, clinicians should strongly consider treating based on clinical suspicion rather than waiting for confirmatory testing. $B$ pertussis is considered contagious from the start of the catarrhal stage through the third 
week, after the onset of the paroxysmal phase, or until 5 days after the start of appropriate antibiotic treatment. ${ }^{25}$ Antibiotic treatment that is started late does not alter the course of the illness and is unnecessary because pertussis is no longer considered infectious after $\sim 21$ days.

Macrolides are first-line agents for the treatment of pertussis, with trimethoprimsulfamethoxazole being used when macrolides are contraindicated. Erythromycin was traditionally prescribed for 14 days, but, because of significant side effects and the lack of most people's ability to comply with a 4-times-per-day medication, azithromycin is more often chosen for treatment. In confirmed cases of pertussis, teammates and coaches should receive postexposure prophylaxis with the same macrolide treatment course. The American College of Chest Physicians (ACCP) states that once treatment of pertussis is initiated, the individual needs to be isolated for the first 5 days of antibiotic treatment. Therefore, athletes with pertussis need to be removed from contact with teammates and staff. Health care providers are mandated to report any confirmed cases. ${ }^{25,27}$

\section{Prophylaxis}

There continue to be high rates of pertussis cases among teens and young adults despite improved immunization rates. These high rates are thought to be in part caused by a change from a live pertussis vaccine to an acellular version of the vaccine in the 1990s. ${ }^{24}$ Based on these continued high rates of infection, the Advisory Council on Immunization Practices (ACIP) recommends a booster vaccine for adolescents and adults. ${ }^{27,28}$ ACIP recommends a single Tdap dose for persons aged 11 to 18 years who have completed the primary series and for adults 19 to 64 years regardless of their last vaccine tetanus or diphtheria toxoid. In addition, pregnant women should receive a booster with each pregnancy, preferably between 27 and 36 weeks' gestation. ${ }^{28}$ In the athletic setting, providers should be educating their athletes and staff about the importance of this vaccination.

\section{Influenza}

Influenza is an extremely contagious viral respiratory illness that can spread quickly through an athletic program. The virus is easily transmitted via respiratory droplets, causing athletes to be at increased risk based on their close proximity to others during practice, competitions, and travel.

\section{Cause}

Influenza subtypes A and B can be identified by rapid nasal swabs. Type B viruses only infect humans and mutate 2 to 3 times slower, resulting in a classically weaker strain that does not cause rapid spread. However, type $A$ viruses are more virulent and can have many different animal hosts. The 2009 pandemic of $\mathrm{H} 1 \mathrm{~N} 1$ was credited with up to 403,000 hospitalizations, compared with the 200,000 seen in a typical flu season, and highlighted the challenges of not having an available vaccine against this influenza $A$ strain. ${ }^{29}$ Despite this, the concerted efforts of the US health care system to guide strong educational initiatives on hand washing, adherence to US Centers for Disease Control and Prevention (CDC) isolation guidelines, and the early reporting of symptoms helped to create awareness and contained many $\mathrm{H} 1 \mathrm{~N} 1$ outbreaks at the high school, collegiate, and professional sports levels. ${ }^{30}$

\section{Diagnosis}

Classic influenza patients present with fever, dry cough, headache, and myalgias. Additional complaints can include a sore throat, rhinorrhea, and congestion. Diagnostic testing for influenza is typically not required in the care of the general 
population; however, confirming the diagnosis in athletes can be invaluable in prevention of a larger outbreak within an athletic program. Nasal washings or a pharyngeal swab should be obtained in an athlete presenting with the presumed index case during the influenza season. Once the index case is confirmed, any additional athletes with influenzalike symptoms can be presumed to also have influenza.

\section{Treatment}

Otherwise healthy individuals infected with influenza usually have complete resolution with only symptomatic treatment. ${ }^{31}$ Symptom improvement is seen between days 3 and 7, although cough and malaise can last days longer. Neuraminidase inhibitors (oseltamivir and zanamivir) can be used to treat influenza A and B, but in order to provide maximum effectiveness these medications need to be started within 48 hours of symptom onset. ${ }^{32,33}$ Resistance to these medications is variable and changes over time.

Neuraminidase inhibitors are often considered for chemoprophylaxis in high-risk household contacts. In the $2009 \mathrm{H} 1 \mathrm{~N} 1$ outbreak, athletes did not qualify for chemoprophylaxis based on CDC guidelines because they were not considered high-risk contacts, mainly because of a fear of antiviral shortages during the pandemic. In situations in which medication shortages are not a concern, clinicians should consider prophylaxis of an in-season sports team and their close contacts if a team member has confirmed influenza.

\section{Prophylaxis}

Vaccination against influenza is the most important prevention strategy. ACIP recommends universal vaccination for those greater than 6 months of age. ${ }^{34}$ Athletes and associated coaching staff members should be highly encouraged to obtain an influenza vaccine early because development of immunoprotection can take up to 5 weeks. In addition, vaccines should generally be scheduled in the off season, or as far away from important competitions as is possible.

\section{Respiratory Tract Infections and General Guidelines For Return To Play}

Athletes with mild viral URTI can often continue to train and compete as tolerated provided that the severity and symptoms of the illness do not worsen with exercise. ${ }^{19}$ Absolute contraindications to participation include fever, hypoxia, and dehydration. Practitioners should also take note of any athlete with unexplained sinus tachycardia because this is frequently the only sign of a viral-induced myocarditis after URTI. ${ }^{35}$

The so-called neck check has long been used as a guideline for when athletes may return to sport. If the symptoms are all above the neck, such as with rhinorrhea, sore throat, and nasal congestion, the athlete can attempt a return to activity. The athlete should start with a brief attempt at light exercise for 10 to 15 minutes, which can then be increased as tolerated assuming there is no worsening of the athlete's symptoms. If symptoms exist that are below the neck, such as fever, malaise, and gastrointestinal symptoms, the athlete should be kept from participation until symptoms have resolved. ${ }^{20}$ Fever is a particularly concerning symptom that should not be masked with medication to allow participation. Athletes should be afebrile for at least 24 hours off any antipyretics before consideration for return to play.

When treating a bacterial infection such as sinusitis or pharyngitis, the athlete should be afebrile and on antibiotics for at least 24 hours before considering return to participation. ${ }^{35}$ After this, a short trial of light activity can be undertaken and, if there is no effect on symptoms, then participation may be continued. However, if there is 
aggravation of significant symptoms, activity should be halted. Progression back to activity should be tailored to match the degree of illness that the athlete experienced. A good general rule of thumb is that for every day missed of training, the athlete should allow 2 to 3 days of graded return. The progression should also increase in small increments along the lines of $10 \%$ at a time, with frequency being increased first, followed by duration, and then intensity ${ }^{35}$ (Fig. 4).

\section{GASTROINTESTINAL}

\section{Traveler's Diarrhea}

Traveler's diarrhea (TD) is an illness that affects up to $40 \%$ of travelers to resourcelimited countries or regions. This risk includes athletes who travel to compete at the national or international level. Although TD is usually self-limited, the risk of secondary dehydration can adversely affect the athlete's ability to train and compete. Classically, TD presents with 3 or more unformed stools, nausea, vomiting, fever, abdominal cramping, or bloody stools. Most cases occur within the first 4 to 14 days of travel and last between 1 and 5 days. ${ }^{36}$

\section{Cause}

Acute TD can be caused by 3 different infectious agents: bacteria, viruses, or parasites. About $90 \%$ of cases are bacterial, with most of those being caused by enterotoxic Escherichia coli. ${ }^{37}$ Additional bacterial pathogens to consider include Salmonella species, Shigella species, Vibrio species, and Campylobacter species. Viruses cause up to $10 \%$ of TD cases, with Norovirus being the most frequent cause in adults. Parasitic organisms should also be considered in athletes with symptoms lasting longer than 7 days. Although only accounting for a small percentage of TD overall, common parasites include Giardia lamblia, Cryptosporidium parvum, and Cyclospora cayetanensis. ${ }^{9}$

\section{Diagnosis}

The diagnosis of TD is typically made clinically and the pathogen is rarely isolated before symptoms resolve on their own. The diagnosis and approach to treatment used to be based on the number of unformed stools but now is based on a functional classification scheme (Fig. 5). Stool cultures should be obtained if the TD lasts greater than 7 days or the patient has fever or colitis symptoms (fever, tenesmus, urgency, cramping, or bloody diarrhea). ${ }^{37,38}$

\section{Treatment}

The mainstay of treatment of TD is fluid replacement. Antibiotic therapy should be reserved for athletes that develop moderate to severe diarrhea, which is clinically classified by the International Society of Travel Medicine as distressing and interfering with planned activities; fever; or blood, pus, or mucus in the stool. Self-treatment with antibiotics for milder cases has been shown to increase microbial resistance. ${ }^{39}$ In general, fluoroquinolones are avoided for treatment of TD in the athletic setting, because of potential effects on the musculoskeletal system, including the rare but worrisome risk of tendon rupture in athletes. Azithromycin has been shown to be as effective for TD as fluoroquinolones and is now the preferred agent. ${ }^{40}$ Azithromycin is given as a 1000-mg single dose or as $500 \mathrm{mg}$ daily for 3 days. In TD caused by $E$ coli, rifaximin has been shown to be effective; however, it is not for use with any febrile diarrhea or dysentery. ${ }^{41}$ If a parasitic cause is suspected, metronidazole $500 \mathrm{mg} 3$ times daily for 5 days is the preferred regimen. The use of antimotility agents such as loperamide and diphenoxylate has been considered controversial in the past, but it is now generally accepted as safe when taken with an antibiotic. ${ }^{9}$ More conservative 


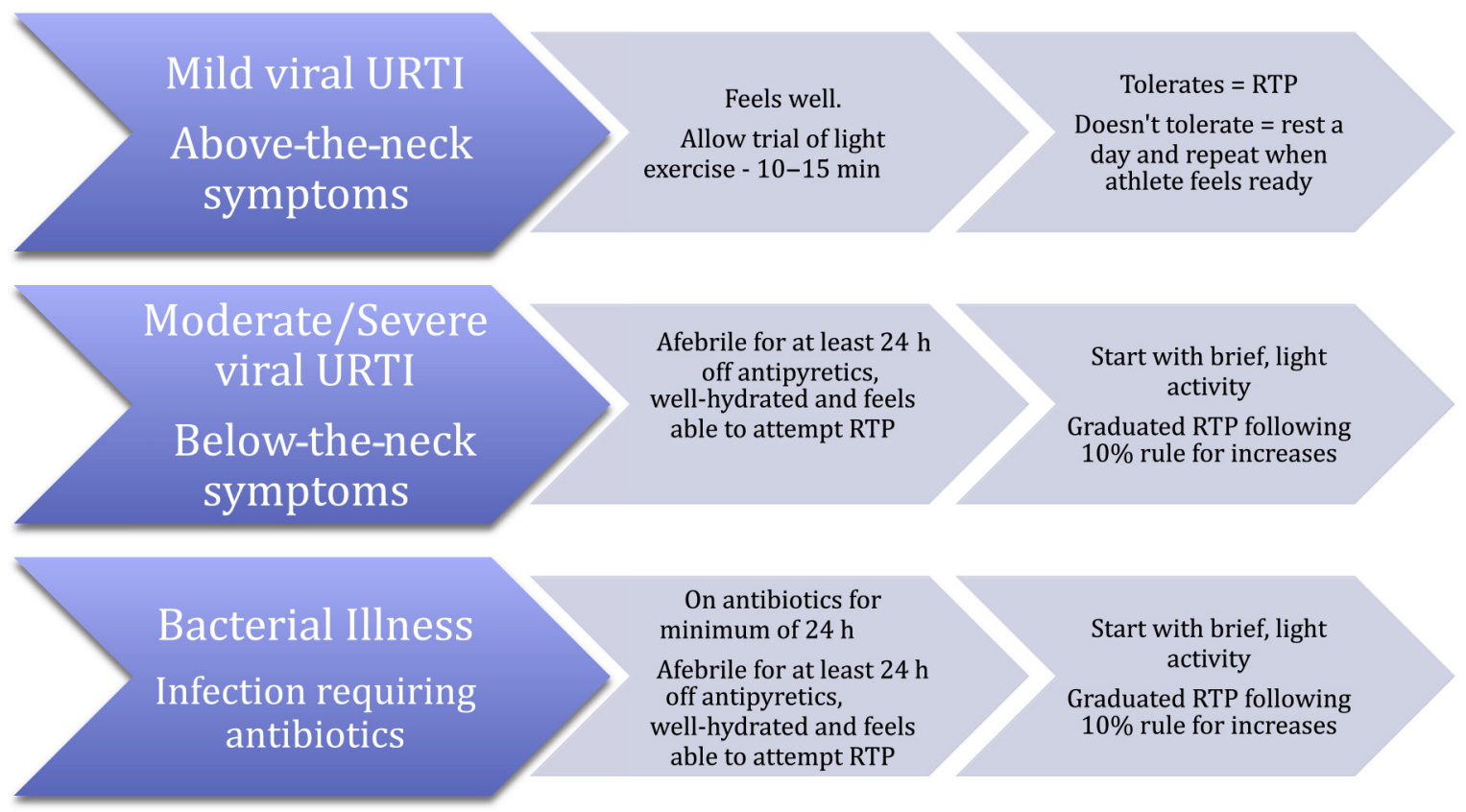

Fig. 4. General approach to return to play after acute illness in athletes. Specific infections may require additional considerations not listed here. RTP, return to play. (Adapted from Jaworski CA, Pyne DB. Upper respiratory tract infections: Considerations in adolescent and adult athletes. UpToDate. Accessed November 26, 2018.) 


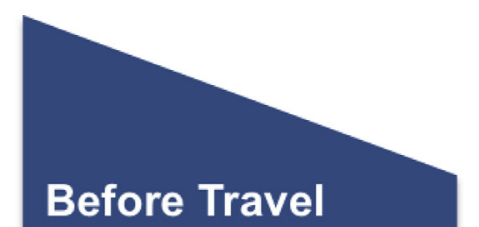

-Counselling on risk and first steps of treatment of TD

-Prophylaxis if indicated

-Empiric treatment provided

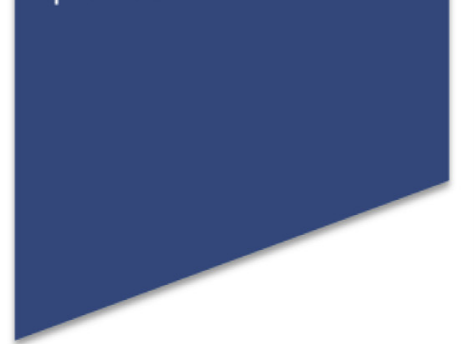

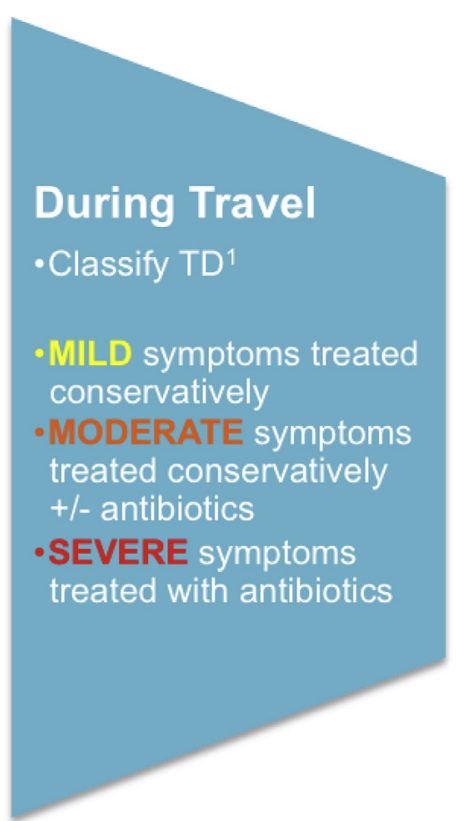

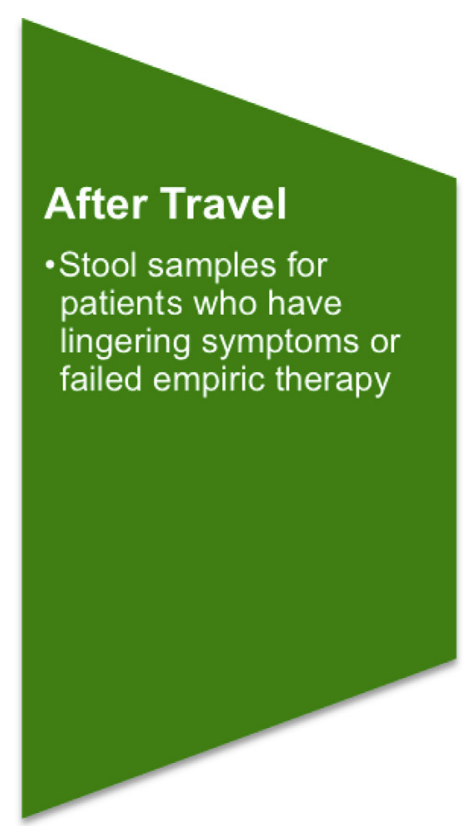

Fig. 5. Management of TD. ${ }^{1}$ Functional classification: mild, tolerable and not distressing, does not interfere with activities; moderate, distressing or interferes with activities; severe, incapacitating symptoms that prevent planned activities. 
recommendations for use in athletes suggest reserving it for use only preceding a competition or during a long trip. ${ }^{42}$ A summary of the recommendations for TD treatment can be found in Table 2.

\section{Prophylaxis and special considerations}

Although antibiotics can be used effectively as prophylaxis in TD, they should not be used routinely. Antibiotic prophylaxis should be reserved for athletes that have underlying health conditions, such as severe inflammatory bowel disease, advanced human immunodeficiency virus, or complicated organ transplant, that would put them at high risk of morbidity if they developed TD. If prophylaxis is needed for an athlete, rifaximin is the antibiotic currently recommended at either $200 \mathrm{mg}$ daily, twice daily, or 3 times daily because of a much lower side effect profile than the fluoroquinolones. ${ }^{43}$ Before travel to high-risk regions, athletes should be educated on prudent selection of food and drinks. Selecting only bottled water or carbonated canned drinks, both consumed from the bottle with a straw rather than from a glass, as well as only eating fully cooked hot food and fruit that is peeled by the eater can minimize risk. Avoidance of buffets, condiments, ice, and food provided on international return flights are additional measures that should be taken while athletes are traveling. Of course, proper handwashing and avoidance of sharing utensils or glassware are also necessary to minimize risk.

\section{Return to play}

The return-to-play plan can be initiated once an athlete is afebrile, rehydrated, and back to tolerating solid foods with no residual gastrointestinal symptoms. Care should be taken to progress slowly through conditioning and then more intense training to allow for any possible deconditioning that occurred, following the same guidelines as outlined for URTIs.

\section{GENITOURINARY}

\section{Urinary Tract Infections}

Urinary tract infection (UTI) is a frequently seen condition that affects women much more often than men. One-third of all women experience at least $1 \mathrm{UTI}$ before the age of 24 years, and is therefore a common reason for female high school and college athletes to seek medical attention. ${ }^{44}$

\begin{tabular}{|c|c|c|c|}
\hline \multicolumn{4}{|c|}{$\begin{array}{l}\text { Table } 2 \\
\text { Approved treatment regimens for traveler's diarrhea }\end{array}$} \\
\hline Agent & Dose (mg) & Duration & Comment \\
\hline Azithromycin & $\begin{array}{l}1000 \text { once } \\
500 \text { daily }\end{array}$ & $\begin{array}{l}\text { Single dose } \\
3 \mathrm{~d}\end{array}$ & $\begin{array}{l}\text { Preferred for dysentery, febrile diarrheas, } \\
\text { south east Asia travelers, pregnant } \\
\text { women }\end{array}$ \\
\hline $\begin{array}{l}\text { Levofloxacin } \\
\text { Ciprofloxacin } \\
\text { Ofloxacin }\end{array}$ & $\begin{array}{l}500 \text { daily } \\
750 \text { once } \\
500 \text { twice daily } \\
400 \text { daily }\end{array}$ & $\begin{array}{l}\text { Single or } 3 d \\
\text { Single dose } \\
3 d\end{array}$ & $\begin{array}{l}\mathrm{FQ} \text { are associated with tendon rupture } \\
\text { and Clostridium difficile }\end{array}$ \\
\hline Rifaximin & 2003 times daily & $3 d$ & $\begin{array}{l}\text { Not used with dysentery or febrile } \\
\text { diarrhea }\end{array}$ \\
\hline Metronidazole & 5003 times daily & $5 d$ & When parasitic infection is suspected \\
\hline
\end{tabular}

Abbreviation: $\mathrm{FQ}$, fluoroquinolone. 


\section{Cause}

$E$ coli is the most common cause of UTI in both men and women and accounts for $75 \%$ to $95 \%$ of cases in women. Less common pathogens include other Enterobacteriaceae, such as Klebsiella pneumoniae and Proteus mirabilis. In athletes with recent hospitalizations or antimicrobial use, organisms such as Pseudomonas, enterococci, and staphylococci should be considered as well. ${ }^{45}$

\section{Diagnosis}

The diagnosis of UTI can often be accomplished by patient history alone. Female athletes presenting with symptoms of dysuria and frequency have a $90 \%$ probability of UTI and may be treated empirically without further testing. Cystitis in male athletes and atypical/vague symptoms in either gender warrant laboratory testing with urinalysis and urine culture to confirm the diagnosis. ${ }^{46}$

\section{Treatment}

First-line antimicrobial agents include trimethoprim-sulfamethoxazole (TMP-SMX) and nitrofurantoin. Choice of agent often comes down to factors such as patient allergies, tolerance of the medication, or local resistance patterns. Of note, TMP-SMX has seen a large increase in the rate of resistance in the past 30 years. ${ }^{47}$ Resistance rates vary based on geography, but TMP-SMX is still considered a first-line choice when rates are less than $20 \% .{ }^{47}$ Women with uncomplicated infection are treated with a 3-day course of antibiotics. ${ }^{48,49}$ Men with cystitis require both a urinalysis and urine culture for their work-up, along with a 7-day course of therapy. ${ }^{50}$

\section{Prophylaxis}

Several studies have suggested that drinking cranberry juice may decrease the incidence of UTIs. A recent meta-analysis from 2017 found that cranberry reduced the risk for UTI by $26 \%$ in otherwise healthy nonpregnant women with a history of UTIs. Studies reviewed were small in sample size, most with fewer than 300 participants. A larger, higher-quality study is needed for further investigation. ${ }^{51}$

\section{Return to play}

Athletes should be restricted from participation until they are afebrile, hydration is restored, and urinary symptoms have resolved. Uncomplicated UTI in female athletes should not significantly hamper training if treatment is started the onset of symptoms. More serious cases require the athletes to have completed their antibiotic treatment and may warrant a graduated return to participation to account for possible deconditioning.

\section{Sexually transmitted infections}

Sexually transmitted infections continue to plague society, with individuals 15 to 24 years old accounting for half of all new infections. Because many athletes are within this age range, educational initiatives are paramount in preventing spread of disease. ${ }^{52}$

\section{Cause}

In 2017, the CDC reported that nearly 2.3 million cases of chlamydia, gonorrhea, and syphilis were diagnosed in the United States, marking the fourth consecutive year of sharp increases in these diseases. ${ }^{52}$ Regardless, human papillomavirus (HPV) is still the most common sexually transmitted disease despite vaccine availability. 


\section{Diagnosis}

Symptomatic athletes or those exposed to sexually transmitted diseases should be tested. For routine health maintenance, the United States Preventive Services Task Force (USPSTF) recommends screening for sexually transmitted diseases in asymptomatic individuals according to Table 3 . All sexually active women up to the age of 24 years, or older women that are at increased risk, should be screened for chlamydia and gonorrhea. However, for asymptomatic men, there is insufficient evidence to screen. Syphilis is tested for in any individual deemed to be at increased risk, including suspected exposure, decreased immune system, or pregnancy. HPV is only screened for in women between the ages of 30 and 65 years in the form of cotesting during pap smears. Before the age of 30 years, most women can clear HPV infections, therefore it is not recommended to routinely test. ${ }^{53}$

\section{Treatment}

The CDC recommendations for treatments for sexually transmitted diseases are listed in Table 4. Treatment of gonorrhea now includes dual-antibiotic therapy with the addition of azithromycin because of emerging antibiotic resistance to ceftriaxone alone. In the treatment of syphilis, the only approved therapy is penicillin by intramuscular injection. For individuals allergic to penicillin, the recommendation is to undergo desensitization because there is no alternative medication. HPV is managed with lesion destruction, including cryotherapy and topical erosive agents. ${ }^{53}$

\section{Prophylaxis}

The USPSTF recommends behavioral counseling for all sexually active adolescents and adults with safe sex practices as a preventive measure for sexually transmitted diseases. In addition, there is currently a vaccine available for both men and women to protect against HPV. Gardasil is recommended starting at age 9 years, and recent change in US Food and Drug Administration regulations allow it to be administered up to age 45 years. Although the vaccine does not protect against all strains of the HPV virus, it offers protection against several of the high-risk strains. ${ }^{52}$

\section{Return to Play}

Return-to-play guidelines are based on the cause and severity of infection. Uncomplicated infections, such as chlamydial or gonorrheal urethritis/cervicitis/rectal disease, rarely warrant exclusion from participation. Any complications, such as epididymitis, pelvic inflammatory disease, or disseminated gonococcal disease, should result in the athlete being held from competition until all symptoms have

\begin{tabular}{|c|c|c|}
\hline \multicolumn{3}{|c|}{$\begin{array}{l}\text { Table } 3 \\
\text { United States Preventive Services Task Force recommendations for screening for sexually } \\
\text { transmitted diseases }\end{array}$} \\
\hline & \multicolumn{2}{|c|}{ USPSTF Recommendations for Screening } \\
\hline STD & Women & Men \\
\hline Chlamydia & $\begin{array}{l}\text { Up to age } 24 \text { y if sexually active, or older if } \\
\text { increased risk }\end{array}$ & Insufficient evidence \\
\hline Gonorrhea & $\begin{array}{l}\text { Up to age } 24 \text { y if sexually active, or older if } \\
\text { increased risk }\end{array}$ & Insufficient evidence \\
\hline Syphilis & Any at increased risk for infection & Any at increased risk for infection \\
\hline HPV & Every $5 \mathrm{y}$ in ages $30-60 \mathrm{y}$ with pap smear & Not indicated \\
\hline
\end{tabular}

Abbreviation: STD, sexually transmitted disease. 


\begin{tabular}{|l|}
\hline $\begin{array}{l}\text { Table } 4 \\
\text { United States Centers for Disease Control and Prevention recommended treatment regimens } \\
\text { for sexually transmitted disease }\end{array}$ \\
\begin{tabular}{ll} 
STD & Recommended Treatment Regimen \\
\hline Chlamydia & $\begin{array}{l}\text { Azithromycin } 1 \mathrm{~g} \text { once, or } \\
\text { Doxycycline } 100 \mathrm{mg} \text { twice daily for } 7 \mathrm{~d}\end{array}$ \\
\hline Gonorrhea & $\begin{array}{l}\text { Ceftriaxone } 250 \mathrm{mg} \text { intramuscularly, pus } \\
\text { Azithromycin } 1 \mathrm{~g} \text { once or doxycycline } 100 \mathrm{mg} \text { twice daily for } \\
7 \mathrm{~d}\end{array}$ \\
\hline Syphilis & Benzathine penicillin G 2.4 million units IM \\
\hline Primary and secondary & Benzathine penicillin G 7.2 million units IM given over 3 doses \\
\hline Tertiary & each 1 wk apart \\
\hline HPV & Lesion destruction \\
\hline
\end{tabular}
\end{tabular}

Abbreviation: IM, intramuscular.

resolved. Once symptoms are resolved, the athlete can partake in a graduated return-to-play progression. ${ }^{52}$

\section{SUMMARY}

Understanding the impact that an acute illness can impart on an athlete's training and performance, as well as the caveats in creating a treatment and return-to-play plan, is essential when providing care to athletes. The general principles of returning an athlete to training should center on ensuring a gradual progression that takes into account any deconditioning that occurred over the course of the illness. Staying up to date on the best treatment approaches as well as monitoring for any signs or symptoms of overtraining helps to keep athletes in the game.

\section{REFERENCES}

1. Gleeson M. Immune function in sport and exercise. J Appl Physiol 2007;103: 693-9.

2. Nieman DC. Exercise, infection and immunity. Int J Sports Med 1994;15:S131-41.

3. Campbell JP, Turner JE. Debunking the myth of exercise-induced immune suppression: Redefining the impact of exercise on immunological health across the lifespan. Front Immunol 2018;9:648.

4. Ekblom B, Ekblom O, Malm C. Infectious episodes before and after a marathon race. Scand J Med Sci Sports 2006;16:287.

5. Hellard P, Avalos M, Guimaraes F, et al. Training-related risk of common illnesses in elite swimmers over a 4-year period. Med Sci Sports Exerc 2015;47:698-707.

6. Veugelers KR, Young WB, Fahrner B, et al. Different methods of training load quantification and their relationship to injury and illness in elite Australian football. J Sci Med Sport 2016;19:24-8.

7. Mårtensson S, Nordebo K, Malm C. High training volumes are associated with a low number of self-reported sick days in elite endurance athletes. J Sports Sci Med 2014;13:929-33.

8. Malm C. Susceptibility to infections in elite athletes: the S-curve. Scand J Med Sci Sports 2006;16:4-6. 
9. Jaworski CA, Donahue B, Kluetz J. Infectious disease. Clin Sports Med 2011; 30:575.

10. Mujika I, Padilla S. Detraining: Ioss of training-induced physiological and performance adaptations. Part I. Sports Med 2000;30:79-87.

11. Lorenc TM, Kernan MT. Lower respiratory infections and potential complications in athletes. Curr Sports Med Rep 2006;5(2):80-6.

12. Mujika I, Padilla S. Detraining: loss of training-induced physiological and performance adaptations. Part II. Sports Med 2000;30:145-54.

13. Schwellnus MP, Schwellnus MP, Jeans A, et al. Exercise and infections. In: Schwellnus MP, editor. The Olympic textbook of medicine in sport. Oxford: Wiley-Blackwell; 2008. p. 344-64.

14. Schwellnus M, Soligard T, Alonso J-M, et al. How much is too much? (Part 2) International Olympic Committee consensus statement on load in sport and risk of illness. Br J Sports Med 2016;50:1043-52.

15. Fry RW, Morton AR, Keast D. Overtraining in athletes. An update. Sports Med 1991;12:32-65.

16. Orhant E, Carling C, Cox A. A three-year prospective study of illness in professional soccer players. Res Sports Med 2010;18(3):199-204.

17. Mountjoy M, Junge A, Alonso JM, et al. Sports injuries and illnesses in the 2009 FINA World Championships (Aquatics). Br J Sports Med 2010;44(7):522-7.

18. Castellani JW, Brenner IK, Rhind SG. Cold exposure: human immune responses and intracellular cytokine expression. Med Sci Sports Exerc 2002;34:2013-20.

19. Metz JP. Upper respiratory tract infections: who plays, who sits? Curr Sports Med Rep 2003;2:84-90.

20. Eichner ER. Infection, immunity, and exercise: what to tell your patients. Physician Sports Med 1993;21:125.

21. WADA prohibited list. Available at: http://www.wada-ama.org/en/what-we-do/theprohibited-list. Accessed November 26, 2018.

22. Braman SS. Chronic cough due to acute bronchitis: ACCP evidence-based clinical practice guidelines. Chest 2006;129(1 suppl):955-1035.

23. Smoot MK, Hosey RG. Pulmonary infections in the athlete. Curr Sports Med Rep 2009;8(2):71-5.

24. Centers for Disease Control and Prevention. Recommended antimicrobial agents for the treatment and postexposure prophylaxis of pertussis. Available at: https:// www.cdc.gov/mmwr/preview/mmwrhtml/rr5414a1.htm. Accessed November 26, 2018.

25. Centers for Disease Control and Prevention. Pertussis treatment. Available at: https://www.cdc.gov/pertussis/clinical/treatment.html. Accessed November 26, 2018.

26. Cornia PB, Hersh AL, Lipshy BA, et al. Does this coughing adolescent or adult patient have pertussis? JAMA 2010;304:890-6.

27. Liang JL, Tiwari T, Moro P, et al. Prevention of pertussis, tetanus, and diphtheria with vaccines in the United States: recommendations of the Advisory Committee on Immunization Practices (ACIP). MMWR Recomm Rep 2018;67(No. RR-2): 1-44.

28. Centers for Disease Control and Prevention. Pertussis: summary of vaccine recommendations. Available at: http://www.cdc.gov/vaccines/vpd-vac/pertussis/ recs-summary.htm. Accessed November 26, 2018.

29. Centers for Disease Control and Prevention. Updated CDC estimates of 2009 $\mathrm{H} 1 \mathrm{~N} 1$ influenza cases, hospitalizations and deaths in the United States, April 
2009-April 10, 2010. Available at: http://www.cdc.gov/h1n1flu/estimates_2009_ h1n1.htm. Accessed December 14, 2010.

30. Dawood FS, Jain S, Finelli L, et al, Novel Swine-Origin Influenza A (H1N1) Virus Investigation Team. Emergence of a novel swine-origin influenza A ( $11 \mathrm{~N} 1)$ virus in humans. N Engl J Med 2009;360:2605-15.

31. Harper SA, Bradley JS, Englund JA, et al. Seasonal influenza in adults and children-diagnosis, treatment, chemoprophylaxis, and institutional outbreak management: clinical practice guidelines of the Infectious Diseases Society of America. Clin Infect Dis 2009;48:1003-32.

32. Jefferson $T$, Jones M, Doshi $P$, et al. Neuraminidase inhibitors for preventing and treating influenza in healthy adults: systemic review and meta-analysis. BMJ 2009;339:b5106.

33. Treanor JJ, Hayden FG, Vrooman PS, et al. US Oral Neuraminidase Study Group. Efficacy and safety of the oral neuraminidase inhibitor oseltamivir in treating acute influenza: a randomized controlled trial. JAMA 2000;283:1016-24.

34. Advisory Committee on Immunization Practices. Influenza ACIP vaccine recommendations. Available at: https://www.cdc.gov/vaccines/hcp/acip-recs/vaccspecific/flu.html. Accessed November 26, 2018.

35. Jaworski CA, Pyne DB. Upper respiratory tract infections: considerations in adolescent and adult athletes. UpToDate. Available at: https://www.uptodate. com/contents/upper-respiratory-tract-infections-considerations-in-adolescentand-adult-athletes. Accessed November 26, 2018.

36. Hill DR. Occurrence and self-treatment of diarrhea in a large cohort of Americans traveling to developing countries. Am J Trop Med Hyg 2000;62:585-9.

37. DuPont HL, Ericsson CD. Prevention and treatment of traveler's' diarrhea. N Engl J Med 1993;328:1821-7.

38. Goodgame R. Emerging causes of traveler's diarrhea: Cryptosporidium, Cyclospora, Isospora, and Microsporidia. Curr Infect Dis Rep 2003;5:66-73.

39. Kantele A, Laaveri T, Mero S, et al. Antimicrobials increase traveler's risk of colonization by extended-spectrum betalactamase-producing Enterobacteriaceae. Clin Infect Dis 2015;60(6):837.

40. Adachi JA, Ericsson CD, Jiang ZD, et al. Azithromycin found to be comparable to levofloxacin for the treatment of US travelers with acute diarrhea acquired in Mexico. Clin Infect Dis 2003;37:1165-71.

41. Adachi JA, DuPont HL. Rifaximin: a novel nonabsorbed refamycin for gastrointestinal disorders. Clin Infect Dis 2006;42:541-7.

42. Murphy GS, Bodhidatta L, Echeverria P, et al. Ciprofloxacin and loperamide in the treatment of bacillary dysentery. Ann Intern Med 1993;118:582-6.

43. Riddle MS, Connor BA, Beeching NJ, et al. Guidelines for the prevention and treatment of traveler's' diarrhea: a graded expert panel report. J Travel Med 2017:24:S57.

44. Dielubanza EJ, Schaeffer AJ. Urinary tract infections in women. Med Clin North Am 2011;95:27-41.

45. Echols RM, Tosiello RL, Haverstock, et al. Demographic, clinical, and treatment parameters influencing the outcome of acute cystitis. Clin Infect Dis 1999; 29(1):113.

46. Bent S, Nallamothu BK, Simel DL, et al. Does this woman have an acute uncomplicated urinary tract infection? JAMA 2002;287(20):2701.

47. Zhanel GG, Hisanaga TL, Laing NM, et al. Antibiotic resistance in outpatient urinary isolates: final results from the North American urinary tract infection collaborative alliance (NAUTICA). Int J Antimicrob Agents 2006;27:468-75. 
48. Wagenlehner FM, Weidner W, Naber KG. An update on uncomplicated urinary tract infections in women. Curr Opin Urol 2009;19:268-74.

49. Milo G, Katchman E, Paul M, et al. Duration of antibacterial treatment for uncomplicated urinary tract infections in women. Cochrane Database Syst Rev 2005;(2):CD004682.

50. Raynor MC, Carson CC III. Urinary infections in men. Med Clin North Am 2011;95: 43-54.

51. Fu Z, Liska D, Talon D, et al. Cranberry reduces the risk of urinary tract infection recurrence in otherwise healthy women: a systematic review and meta-analysis. J Nutr 2017;147(12):2282-8.

52. Centers for Disease Control and Prevention. New CDC analysis shows step and sustained increases in STDs in recent years. 2018. Available at: https://www. cdc.gov/nchhstp/newsroom/2018/press-release-2018-std-prevention-conference. html. Accessed November 26, 2018.

53. United States Preventive Services Task Force. Available at: https://www. uspreventiveservicestaskforce.org/BrowseRec/Index/browse-recommendations. Accessed November 26, 2018. 